\title{
Prevalence of attention deficit hyperactivity disorder in children with unintentional injuries
}

\author{
H Perera ${ }^{1}$, K C Jeewandra ${ }^{2}$, N Jayasuriya ${ }^{3}$, R Dias $^{4}$ \\ Sri Lanka Journal of Child Health, 2012; 41(1): 20-23 \\ (Key Words: ADHD; unintentional-injuries; injury-proneness; children)
}

\begin{abstract}
Introduction: Attention deficit hyperactivity disorder (ADHD) is characterized by hyperactivity, inattention and impulsiveness. Risk-taking behaviour and accident proneness are well recognized in these children.
\end{abstract}

Objectives: To estimate the prevalence of ADHD among children attending an Accident Service and to describe the injury profile.

Method: Data was gathered from children with unintentional-injuries attending Accident Service on randomly selected days. SNAP IV, an 18-item standardized schedule validated for diagnosis of ADHD, was interviewer-administered to parents. Injury-related data was collected using a semistructured questionnaire.

Results: One hundred and fifty one children, aged 4 to 12 years (mean age 8.5 years), participated in the study. Prevalence of ADHD in this group was $18 \%$. Children with and without ADHD did not differ in mean age and gender distribution. Children with ADHD were more likely to sustain injury needing hospitalization, report previous injury needing hospitalization and were perceived by mothers as injury prone, which were all statistically significant $(\mathrm{p}<0.05)$.

Conclusions: Prevalence of ADHD among children attending an Accident Service was 18\%. Children with ADHD were more likely to sustain injury needing hospitalization $(\mathrm{p}<0.01)$. Children with ADHD were perceived by parents as prone to injury $(\mathrm{p}<0.05)$.

${ }^{1}$ Professor, Department of Psychological Medicine, University of Colombo, ${ }^{2}$ Medical Officer in Psychiatry, ${ }^{3}$ Senior Registrar, Lady Ridgeway Hospital for Children, Colombo, ${ }^{4}$ Senior Lecturer, Department of Surgery, University of Colombo

(Received on 11 February 2011: Accepted on 25 March 2011)

\section{Introduction}

Attention deficit hyperactivity disorder (ADHD) is characterized by hyperactivity, inattention and impulsiveness that are inappropriate to age and pervasive to different settings ${ }^{1}$. A prevalence of $5.1 \%$ was found among hospital based medical and surgical outpatient population of children in Sri Lanka ${ }^{2}$.

The odds of having an accident are 1.7 times greater for children and adolescents with ADHD when compared with controls and it is a significant predictor for accident claims ${ }^{3}$. In a nationally representative study in US, an association was found between ADHD and injury in children, which could not be attributed to other confounding risk factors ${ }^{4}$. A study that examined the relationship between common child psychiatric disorders and unintentional injury found that oppositional defiant disorder (ODD) and ADHD were associated with sustaining burns, accidental poisoning and fractures ${ }^{5}$. Children with ADHD are also said to be more frequent users of a range of medical services when compared to nonADHD children ${ }^{6}$. Furthermore, children with ADHD are likely to sustain multiple injuries and head injuries, the likelihood of self-inflicted injury being $1.3 \%$ vs. $0.1 \%$ when compared with non-ADHD children $^{7}$. Increased risk of sustaining burn injury is found among children with $\mathrm{ADHD}^{8-11}$.

Impulsiveness and vigilance deficit are considered to be the underlying causes and stimulant medication and increased supervision are recommended as preventive measures from further injury'. An association has been found between frequent burns in children and presence of $\mathrm{ADHD}^{12}$. A high prevalence of premorbid ADHD has been found among children presenting with moderate to severe closed head injuries ${ }^{13}$. ADHD, as a predisposing factor, has also been linked to traumatic dental injuries ${ }^{14}$. A study in Sri Lanka found a prevalence of $14.3 \%$ of ADHD in children presenting with self-inserted nasal and aural foreign bodies ${ }^{15}$. 


\section{Objectives}

The objectives of the study were to estimate the prevalence of ADHD among a sample of children attending an Accident Service and describe the difference in the characteristics of injury in children with and without ADHD.

\section{Method}

The study setting was the Accident Service at the Lady Ridgeway Hospital. All children attending the Accident Service with unintentional injuries on randomly selected days between $8 \mathrm{am}$ and $4 \mathrm{pm}$ were included in the study, until the sample size of 150 was reached. It was randomly spread over 70 days to include school days as well as school vacation. The selected children were included irrespective of whether they were treated in the ambulatory setting or hospitalized, and irrespective of any other associated health conditions. Exclusion criteria were the fatalities, self-inflicted injury, and injury where unintentional nature was not clearly established.

SNAP IV (Swanson, Nolan and Pelham, version IV), a standardized tool for assessment of ADHD was used for establishing the diagnosis. SNAP IV is an 18-item norm-referenced checklist that is designed using DSM IV diagnostic criteria ${ }^{1}$ for ADHD. It identifies ADHD as one of three subtypes namely, ñnattentionò, ñhyperactivity / impulsivityò or ñcombinedò, depending on the most prominent clinical feature. Scores for ñcombinedò was used in this study as it includes all 3 cardinal features and best represents the diagnosis of ADHD. SNAP IV was interviewer-administered to the parent or guardian accompanying the child and the responses were recorded. SNAP IV has shown $91 \%$ sensitivity and $88 \%$ specificity when used in specialist child mental health outpatients. To maintain consistency, this tool was administered to parents in all cases by a research assistant with medical training who was trained in the use of SNAP IV. In addition, a semistructured questionnaire was used for collection of (i) bio-data, (ii) data related to injury characteristics and (iii) the presence of developmental problems and learning difficulties in the child. Frequency distribution and significant associations of variables were estimated by cross tabulation.

\section{Results}

Data related to 151 children was available for analysis. They were 4 to 12 years old with a mean age of 8.5years (SD 2.13, median 9 yrs and mode 11 yrs). The majority, $115(76.4 \%)$ were in the age group of 7-11 years. The sample was predominantly male with $113(75.7 \%)$.

Of the 151 children, 27 were diagnosed as ADHD, giving a prevalence of $18 \%$. Mean age of children diagnosed with ADHD was 8.6 years and 21 (78\%) were male. Developmental problems were reported in $02(7.4 \%)$ and learning difficulties in 07 (26\%). None were taking medication and one child reported contact with mental health services. Similar data for children without ADHD is as follows: The mean age was 8.5 years, $93(75 \%)$ were male. Developmental problems and learning difficulties were reported in 03 (2.4\%) and $43(34.7 \%)$ respectively. Table 1 compares injury specific data in children with and without ADHD.

Table I: Comparison of injury specific data in children with and without ADHD

\begin{tabular}{|l|c|c|c|}
\hline \multicolumn{1}{|c|}{ Variable regarding Injury } & $\begin{array}{c}\text { ADHD present } \\
\mathbf{N = 2 7}\end{array}$ & $\begin{array}{c}\text { ADHD not } \\
\text { present N= 124 }\end{array}$ & $p$ \\
\hline Type of Injury & & & $0.669(>0.05)$ \\
Dog bite & $4(14.8 \%)$ & $31(25 \%)$ & \\
Fracture & $7(25.9 \%)$ & $22(17.7 \%)$ \\
Lacerations & $5(18.5 \%)$ & $27(21.8 \%)$ & \\
Cut injury & $4(14.8 \%)$ & $20(16.1 \%)$ & \\
Head injury & $7(25.9 \%)$ & $27(21.8 \%)$ & $0.001(<0.01)$ \\
\hline Injury needing hospitalisation & $23(85.2 \%)$ & $62(50 \%)$ & $0.005(<0.01)$ \\
\hline l-4 previous injuries needing medical attention & $12(44.4 \%)$ & $29(23.4 \%)$ & $0.068(>0.05)$ \\
\hline Past injury related hospitalisation & $11(40.7 \%)$ & $30(24.2 \%)$ & $0.026(<0.05)$ \\
\hline Perceived by parent as prone to injury & $21(77.8 \%)$ & $69(55.6 \%)$ & $0.897(>0.05)$ \\
\hline Place of current injury & & & \\
Home & $15(55.6 \%)$ & $65(52.4 \%)$ & \\
Road & $2(7.4 \%)$ & $13(10.5 \%)$ & \\
School & $7(25.9 \%)$ & $33(26.6 \%)$ & $13(10.5 \%)$ \\
Other & $3(11.1 \%)$ & & \\
\hline
\end{tabular}




\section{Discussion}

The prevalence of ADHD in the study group was over 3 times higher when compared to the reference population of general medical and surgical outpatients $^{2}$ and the general population. This finding is comparable with a prevalence of ADHD of around $20 \%$ found among children with closed head injury ${ }^{13}$. The children who participated in the study did not differ in mean age or gender distribution on the basis of presence or absence of ADHD. In contrast, these two groups of children differed in other respects that were statistically significant (Table 1). Firstly, more children with ADHD were likely to have sustained injuries needing hospitalization, $85.2 \%$ vs $50 \%$, indicating the possibility that the injuries were more severe. This finding is supported by other studies in similar accident and emergency settings ${ }^{7}$. In contrast, a study of preschoolers with ADHD found that they were more at risk of minor injuries but not major injuries when compared to a control group of nonADHD children ${ }^{16}$. Secondly, children with ADHD were more likely to have history of repeated injuries, $44.4 \%$ vs $23.4 \%$. Thirdly, children with ADHD were perceived by parents as prone to injury, which was significant at the level of $p<0.05$. Furthermore, a higher proportion of children with ADHD reported previous injury related hospitalizations, $40.7 \%$ vs $24.2 \%$, when compared to those without ADHD, though this finding did not meet statistical significance. Our study also shows a proportionately higher number of fractures and head injury in children diagnosed with ADHD when compared to children without ADHD, though not a statistically significant difference. Similar findings are reported on association between ADHD and selected injury type such as head injury, burns and other trauma ${ }^{7,9}$. It was interesting to note that proportionately more children without ADHD had learning difficulties though this is a known comorbidity with ADHD. However, it has also been reported that development and cognitive skills do not have a significant association with injury proneness in $\mathrm{ADHD}^{17}$. Also noteworthy is that more than $50 \%$ of children sustained injury at home rather than on the road as reported in other studies ${ }^{7}$, which was true of both ADHD and non-ADHD children. The study cannot comment on the objective measures of injury severity, length of stay in hospital and outcome. Also, we cannot comment on environmental variable that may have acted as confounders that operated in making children with ADHD more vulnerable to injury.

\section{Conclusions}

- Prevalence of ADHD among children attending the Accident Service at the Lady Ridgeway Hospital was $18 \%$.

- More children with ADHD were likely to have sustained injuries needing hospitalization $(\mathrm{p}<0.01)$.

- Children with ADHD were perceived by parents as prone to injury $(\mathrm{p}<0.05)$.

\section{References}

1. Diagnostic and Statistical Manual of Mental Disorders 4th Edition Text Review (DSM IV TR), American Psychiatric Association 2002.

2. Hewage C. Prevalence of attention deficit hyperactivity disorder among medical and surgical outpatient population. MD Psychiatry Thesis 2005.

3. Swenson A, Birnbaum HG, Ben Hamadi R, Greenburg P, Cremieux PY, Secnik K. Incidents and cost of accidents among attention-deficit / hyperactivity disorder patients. $J$ Adolesc Health 2004; 35: 346 e1-9.

4. Pastor PN, Reuban CA. Identified attention deficit/hyperactivity disorder and medically attended nonfatal injuries: US school-age children 1997-2002. Ambul Pediatr 2006; 6: 3844. http://dx.doi.org/10.1016/j.ambp.2005.07.002

5. Rowe R, Maughan B, Goodman R. Childhood psychiatric disorder and unintentional injury: findings from a national cohort study. $J$ Pediatr Psychol 2004; 29: 119-30. http://dx.doi.org/10.1093/jpepsy/jsh015

6. Miller AR, Brehaut JC, Raina P, McGrail KM, Armstrong RW. Use of medical services by methylphenidate-treated children in the general population. Ambul Pediatr 2004; 4: 174-80. http://dx.doi.org/10.1367/A03-031R1.1

7. DiScala C, Lescohier I, Barthel M, Li G. Injuries to children with attention deficit hyperactivity disorder. Pediatrics 1998; 102: 1415-21. http://dx.doi.org/10.1542/peds.102.6.1415

8. Mangus RS, Bergman D, Zeiger M, Coleman JJ. Burn injuries in children with attention deficit / hyperactivity disorder. Burns 2004; 30: 148-50. http://dx.doi.org/10.1016/j.burns.2003.09.020 
9. Fritz KM, Butz C. Attention deficit/hyperactivity disorder and pediatric burn injury: important considerations regarding premorbid risk. Curr Opin Pediatr 2007; 19: 565-9.

http://dx.doi.org/10.1097/MOP.0b013e3282ef49 $\underline{8 \mathrm{c}}$

10. Thomas CR, Ayoub M, Rosenberg L, Robert RS, Meyer WJ. Attention deficit hyperactivity disorder \& pediatric burn injury: a preliminary retrospective study. Burns 2004; 30: 221-3. http://dx.doi.org/10.1016/j.burns.2003.10.013

11. Badger K, Anderson L, Kegan RJ. Attention deficit-hyperactivity disorder in children with burn injuries. J Burn Care and Res 2008; 29: 724-9.

http://dx.doi.org/10.1097/BCR.0b013e31818480 $\underline{\mathrm{e}}$

12. Ghanizadeh A. Small burns among outpatient children and adolescents with attention deficit hyperactivity disorder. Burns 2008; 34: 546-8. http://dx.doi.org/10.1016/j.burns.2007.07.015

13. Gerring JP, Brady KD, Chen A, Vasa R, Grados M, Bandeen-Roche KJ, Bryan RN, Denckla MB. Premorbid prevalence of ADHD and development of secondary ADHD after closed head injury. Journal of the American Academy of
Child and Adolescent Psychiatry 1998; 37: 64754.

http://dx.doi.org/10.1097/00004583-199806000$\underline{00015}$

14. Sabuncuoglu O. Traumatic dental injuries and attention-deficit/hyperactivity disorder: is there a link? Dental Traumatology 2007; 23: 137-42. http://dx.doi.org/10.1111/j.16009657.2005.0043 $\underline{1 . \mathrm{X}}$

15. Perera H, Fernando SM, Yasawardena ADKSN, Karunarathne I. Prevalence of attention deficit hyperactivity disorder (ADHD) in children presenting with self-inserted nasal and aural foreign bodies. International Journal of Pediatric Otorhinolaryngology 2009; 73:1362ï 4. http://dx.doi.org/10.1016/j.ijporl.2009.06.011

16. Byrne JM, Bawden HN, Beattie T, DeWolfe NA. Risk for injury in preschoolers: relationship to attention deficit hyperactivity disorder. Child Neuropsychology 2003; 9: 142-51. http://dx.doi.org/10.1076/chin.9.2.142.14501

17. Schwebel DC, Speltz ML, Jones K, Bardina P. Unintentional injury in preschool boys with and without early onset of disruptive behavior. Journal of Pediatric Psychology 2002; 27: 72737. http://dx.doi.org/10.1093/jpepsy/27.8.727 